\title{
Design of ultrasonic testing device for fatigue damage of pressure vessels
}

\author{
Wenchao LU ${ }^{1}$, Huibin $\mathrm{YANG}^{1, \mathrm{a}}$, Juan $\mathrm{YAN}^{1}$, Chengbo KANG \\ ${ }^{1}$ College of Mechanical and automotive Engineering, Shanghai University of Engineering Science, Shanghai, China
}

\begin{abstract}
The container fatigue damage detection device is researched and designed for the fatigue damage detection requirements of pressure vessels. The hardware design of the detection device, the corresponding detection technology and the functions realized are introduced. The new test performs ultrasonic nondestructive testing by driving five DC servo motors to drive the mechanical part of the test device. Research on the detection system and technology to automate the detection of fatigue damage in pressure vessels
\end{abstract}

\section{Introduction}

Pressure vessels (Figure 1) are prone to fatigue damage due to long-term exposure to alternating stress and high temperature, high pressure and high radiation working conditions, and are important stress-bearing objects ${ }^{[1-3]}$. The ASME Code and the RCC-M Code require full safety inspection of pressure vessels to ensure safe and reliable operation ${ }^{[4-5]}$. Ultrasound nondestructive testing technology is a kind of testing technology with the fastest development speed and the highest frequency of use in modern times. It is widely used in almost all industrial detection fields, especially in nuclear power and other new technology industries ${ }^{[6]}$. At present, it is the trend of the times to detect the fatigue damage of pressure vessels by ultrasonic testing. J.Wang used the small angle longitudinal wave oblique probe ultrasonic testing method to study the internal fatigue crack in the screw thread area of the high pressure cylinder of steam turbine, which improved the detection sensitivity of the screw thread root and fatigue $\operatorname{crack}^{[7]}$. M.R. Sun independently developed a set of reactor pressure vessel main bolt ultrasonic testing system, which improved the detection accuracy and signal-to-noise ratio, solved the coupling agent automatic supply, discharge and recycling problems ${ }^{[8]}$.

At present, manual testing is often used in the field of pressure vessel ultrasonic testing, which is easy to be missed and the accuracy of testing data is not high. Therefore, a set of pressure vessel ultrasonic testing device is designed to realize the automation of pressure vessel fatigue damage detection.

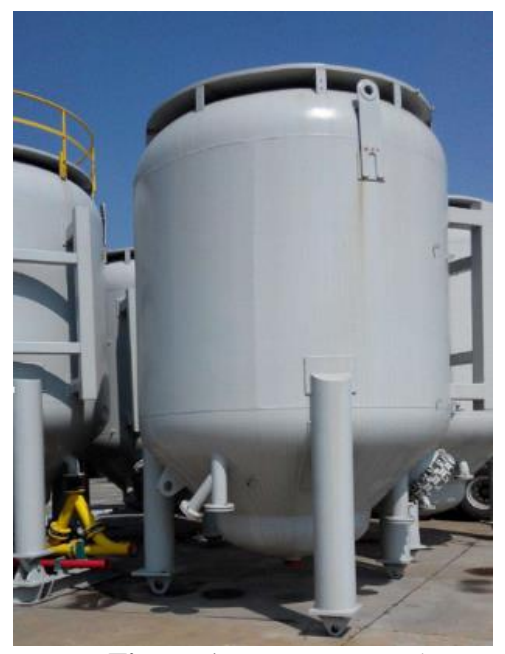

Figure 1. Pressure vessel

\section{Mechanical structure of detection device}

The mechanical structure of pressure vessel detection device mainly includes ball screw, servo motor assembly, base and support frame, four sections of track, slide seat and detection platform (outer frame assembly, detection car frame, detection rod rotation mechanism, moving platform). The equipment can meet the requirements of ASME and RCC-M standards for ultrasonic testing of pressure vessels, and is suitable for ultrasonic testing of various pressure vessels in China. It has high safety control performance, automatically diagnoses faults and prompts for alarms. Respond to automated inspection requirements for the current time period.

The ball screw drive detection tube rotates the platform to realize the axial lifting movement, which drives the ultrasonic detection tube to rise and lower, and the ultrasonic probe is fixed at the end of the detection rod to realize ultrasonic detection; the servo motor 
assembly is rotated by the detection platform in the circumferential direction, and the detection platform is lifted and lowered. The motor, The detection platform circumferential rotating motor, the detection platform lifting motor, the detecting rod radial adjusting motor, the detecting rod lifting motor and the detecting rod rotating motor are composed of five DC servo motors, which drive the detecting rod and the detecting platform to move, and provide the motive force for the movement of the whole system; the base and the frame assembly are supported by the base and the supporting frame The composition provides support for the whole mechanical device and the tested component (pressure vessel); the four-section track is fast-connected by the quickconnecting device and the positioning pin; the "tightly hugs" on the outer wall of the pressure vessel by the flexible clamping mechanism; The auxiliary device realizes rapid positioning; the detecting platform comprises an outer frame assembly, a detecting trolley frame, a detecting rod rotating mechanism and a moving platform; the sliding seat comprises an arc running mechanism, a pressing wheel, a guiding wheel and an eccentric wheel. The outer side of the sliding seat is a guiding wheel, the inner side is an eccentric wheel, and the middle is a bearing wheel; When the slider is installed, the position of the eccentric wheel is the largest between the left and right wheels, the sliding seat is loaded from the side of the track, and then the characteristics of the eccentric wheel are used to press the left and right wheels tightly on the track, detecting The mechanical structure of the device is shown in Figure 2.

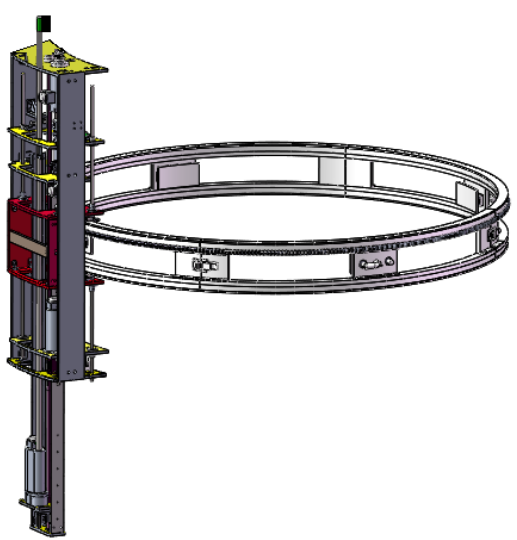

Figure 2. Pressure vessel detection device mechanical structure

\section{Detection device hardware selection}

The pressure vessel detecting device mainly includes a detecting platform, a detecting rod and the like. The driver receives a pulse signal from the motion controller to drive the motion of the servo motor, and the servo motor converts the pulse signal into an angular displacement drive mechanism for detection. Select the appropriate motion controller and driver according to the servo motor type, parameters, power and other specifications. Since the maxon DC motor is a highquality DC motor, it uses high-performance permanent magnets to give the drive a compact structure, high performance and low inertia. And because of the small inertia, DC motors can achieve high acceleration, and maxon is a global leader in high-precision motors and drive systems up to $500 \mathrm{~W}$. So choose the maxon DC motor.

The detecting platform circumferential rotating motor is divided into three stages: the start acceleration phase (duration $0.5 \mathrm{~s}$ ), the constant speed phase (duration $3 \mathrm{~s}$ ), and the braking phase (duration 0.5s). The detecting platform moving speed $(\mathrm{v})$ is $0.05 \mathrm{~m} / \mathrm{s}$, the detecting platform mass $(\mathrm{m})$ is $30 \mathrm{~kg}$, the gear indexing circle diameter (d) is $120 \mathrm{~mm}$, the friction coefficient (f) is 0.05 , and the gear ratio $(\mathrm{R})$ is 12 .

The acceleration a:

$$
\mathrm{a}=\frac{v}{\mathrm{t}}=0.1 \mathrm{~m} / \mathrm{s}^{2}
$$

External force of detecting platform $F_{\mathrm{r}}$ :

$$
F_{\mathrm{r}}=\mathrm{ma}=3 \mathrm{~N}
$$

Detection of gear meshing force $\mathrm{F}$ :

$$
\mathrm{F}=F_{\mathrm{r}}+F_{\mathrm{f}}=18 \mathrm{~N}
$$

Load torque $T_{L}$ :

$$
T_{\mathrm{L}}=F r+\frac{1}{2} m_{1} r^{2}
$$

$m_{1}$ is the mass of the pinion, $r$ is the radius of the pinion, because $\frac{1}{2} m_{1} r^{2}$ can be negligibly small, so the load torque can be expressed as:

$$
\begin{aligned}
& T_{\mathrm{L}}=F r+\frac{1}{2} m_{1} r^{2} \approx F r=1.08 \mathrm{~N} \cdot m \\
& \text { Motor torque } T_{\mathrm{M}}: \\
& T_{\mathrm{M}}=\frac{\tau_{\mathrm{L}}}{R}=0.09 \mathrm{~N} \cdot m
\end{aligned}
$$

Load moment of inertia $/ \mathrm{L}$ :

$$
h_{\mathrm{L}}=\mathrm{mf}(d / 2)^{2}=54 \mathrm{~kg} \cdot \mathrm{cm}^{2}
$$

Conversion to the moment of inertia of the motor shaft $/$ LM :

$$
J_{\mathrm{LM}}=\frac{\mathrm{mf}\left(\frac{d}{2}\right)^{2}}{R^{2}}=0.375 \mathrm{~kg} \cdot \mathrm{cm}^{2}
$$

The required detecting rod rotating motor torque $T_{\mathrm{M}}$ $\geqq 0.09 \mathrm{~N} \cdot \mathrm{m}$, and the moment of inertia $I_{\mathrm{LM}} \geqq 0.375 \mathrm{~kg} \cdot \mathrm{cm}^{2}$.Considering the characteristics of the maxon motor, choose type of the detecting rod rotating motor is maxon RE50 $200 \mathrm{~W} 48 \mathrm{~V}$.

The quality of the lifting detecting platform includes the detecting lever, two motor (the detecting platform lifting motor,the detecting rod lifting motor), belt wheel, lift floor,the total mass (M)is $10 \mathrm{~kg}$, the screw diameter $\left(D_{\mathrm{B}}\right)$ is $25 \mathrm{~mm}$, and the quality is $4.242 \mathrm{~kg}$. Screw lead $\left(P_{\mathrm{B}}\right)$ is $0.02 \mathrm{~m}$. The ratio of deceleration $(\mathrm{R})$ is 4.3 .

The torque of detecting platform lifting motor can be detected :

$$
T_{\mathrm{M}}=\frac{F P_{\mathrm{B}}}{2 \pi R}=0.074 \mathrm{~N} \cdot \mathrm{m}
$$

Load moment of inertia $/_{L}$ :

$$
J_{\mathrm{L}}=J_{\mathrm{W}}+J_{\mathrm{B}}=M\left(\frac{P_{\mathrm{B}}}{2 \pi}\right)^{2}+M_{\mathrm{B}} \frac{\left(D_{\mathrm{B}}\right)^{2}}{8}=4.36 \mathrm{~kg} \cdot \mathrm{cm}^{2}
$$

Conversion to the moment of inertia of the motor shaft $/$ LM:

$$
I_{\mathrm{LM}}=\frac{\mathrm{L}}{R^{2}}=0.2344 .36 \mathrm{~kg} \cdot \mathrm{cm}^{2}
$$

The torque of the detecting platform lifting motor $T_{\mathrm{M}}$ $\geqq 0.074 \mathrm{~N} \cdot \mathrm{m} \quad, \quad$ and the moment of 
inertia $J_{\mathrm{LM}} \geqq 4.36 \mathrm{~kg} \cdot \mathrm{cm}^{2} \quad$.Considering the characteristics of the maxon motor, choose the detecting platform lifting motor is maxon RE50 200W 48V.

Because of the small quality of the detecting rod, combined with the characteristics of maxon motor, the type of detecting rod lifting motor is maxon RE50 200W $48 \mathrm{~V}$.

The load (M) of the detecting rod rotating motor is $0.3 \mathrm{~kg}$, the diameter (d) of the pulley is $80 \mathrm{~mm}$, the friction coefficient $(\mu)$ of the load and platform is 0.6 , and the deceleration ratio $(\mathrm{R})$ is 3.7 .

Torque motor torque $T_{\mathrm{M}}$ :

$$
T_{\mathrm{M}}=\operatorname{Mg} \mu \frac{\left(\frac{\mathrm{D}}{2}\right)}{R}=0.019 \mathrm{~N} \cdot \mathrm{m}
$$

Load moment of inertia $/ \mathrm{L}$ :

$$
I_{\mathrm{L}}=M \mu \frac{(D)^{2}}{8}=1.44 \mathrm{~kg} \cdot \mathrm{cm}^{2}
$$

Conversion to the moment of inertia of the motor shaft / LM :

$$
I_{\mathrm{LM}}=\frac{\mathrm{h}}{R^{2}}=0.105 \mathrm{~kg} \cdot \mathrm{cm}^{2}
$$

The detecting rod rotating motor torque $T_{\mathrm{M}} \geqq$ $0.019 \mathrm{~N} \cdot \mathrm{m}$, and the moment of inertia $I_{\mathrm{LM}} \geqq 0.105 \mathrm{~kg} \cdot \mathrm{cm}^{2}$. Considering the characteristics of maxon motor, choose the detecting rod rotating motor is maxon RE30 $60 \mathrm{~W} 48 \mathrm{~V}$.

The detection rod radial adjustment motor needs to radially displace the detection rod and some accessories with a small mass by $\pm 2 \mathrm{~mm}$ to ensure that the upper ultrasonic probe of the detection rod is close to the outer wall of the pressure vessel. In combination with the characteristics of the maxon motor, the radial adjustment motor model of the detection rod is selected as maxon. RE30 60W 48V.According to the selected servo motor (maxon RE30 60W 48V, maxon RE50 200W 48V), the control system of the ultrasonic detecting device selects the GALIL DMC-2183 motion controller. AMP-20540 amplifier drives the detecting platform circumferential rotating motor, the detecting platform lifting motor, AMP-20440 amplifier drives the detecting rod radial adjusting motor, the detecting rod lifting motor, the detecting rod rotating motor. The GALIL DMC-2183 motion controller can be used to control 8 axes at most. It integrates motion control and servo amplification functions.

\section{4 detection device circuit design}

The overall circuit design of the pressure vessel detection device is shown in Figure 3. It mainly includes the circuit connection of the controller and the motor, the I/O interface and the ultrasonic detector. The GALIL DMC-2183 motion controller communicates with the host computer via an RJ45 Ethernet interface. The DC motor drives GALIL AMP-20540 and AMP-20440 receive pulse signals from the GALIL DMC-2183 motion controller and drive the servo motor motion, as well as control the ultrasonic tester for fatigue damage detection. The servo motor converts the pulse signal into an angular displacement drive mechanism for ultrasonic detection, and the encoder feeds the pulse back to the controller to form a closed loop control in time. The GALIL DMC-2183 motion controller provides a general purpose I/O port for synchronizing with external events, 16 digital inputs and 16 digital outputs. To prevent accidental damage to the main power supply directly connected to the motion controller, the detection device adds a relay to the $\mathrm{I} / \mathrm{O}$ port of the motion controller. The three-loop control is realized in the motion controller, and at the same time, it ensures the grounding is reliable, the motor wire is shielded, and the motor is shielded with metal casing and other anti-interference measures.

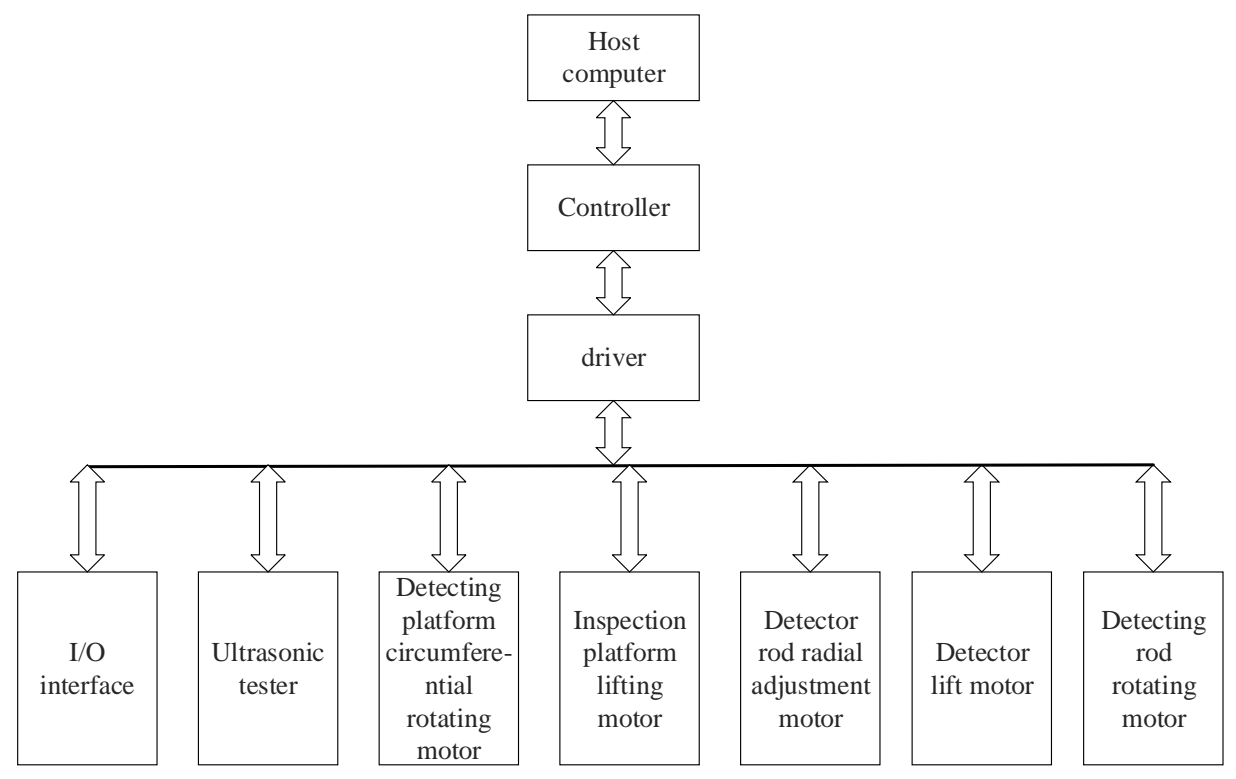

Figure 3. The overall circuit design of the pressure vessel detection device

Taking the design of the circumferential rotating motor circuit driven by the AMP-20540 amplifier as an example, the air plug of the control end and the equipment end is used as a medium to connect, and the resistor module is added to reduce the motor heat generation. The shielded twisted pair grounding is used to ensure the detection device safety. Figure 4 shows the 
circuit design of the AMP-20540 amplifier and platform

circumferential rotating motor.

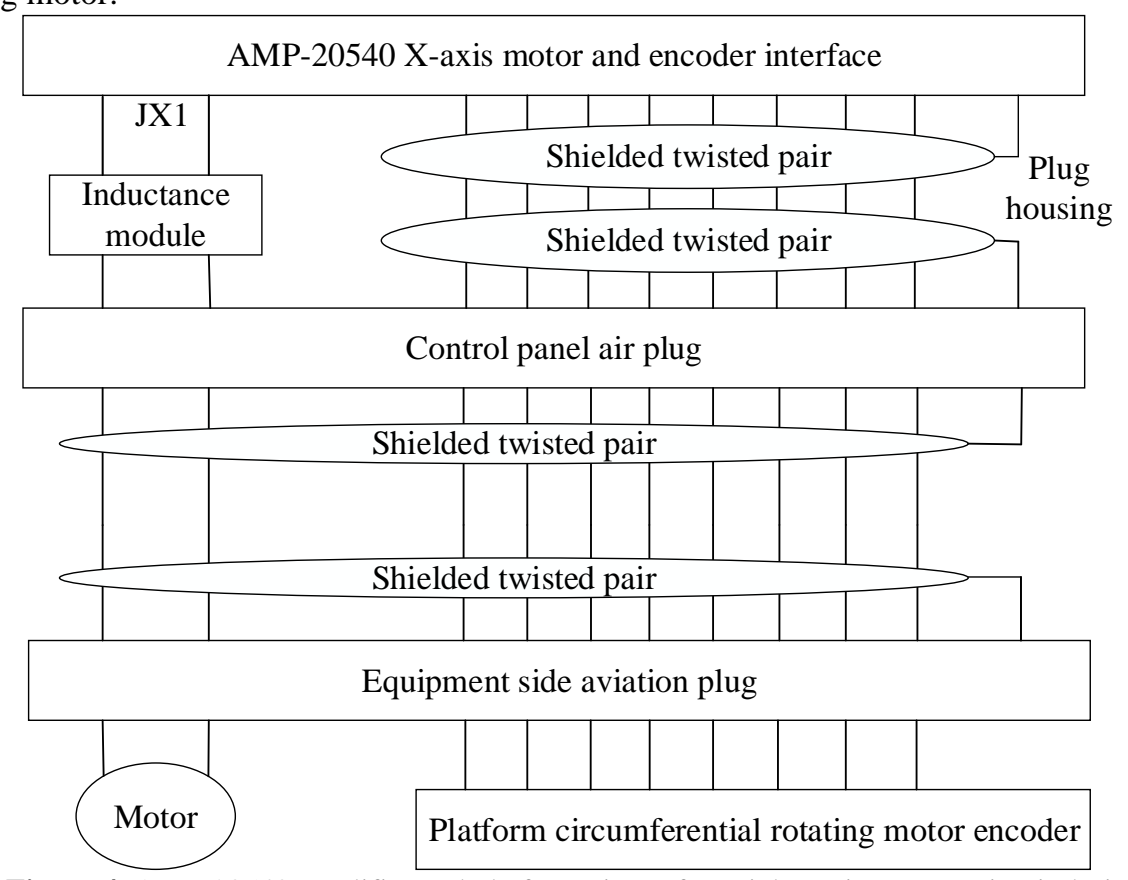

Figure 4. AMP-20540 amplifier and platform circumferential rotating motor circuit design

\section{5 detection process realization}

The pressure vessel ultrasonic testing method described in this paper is a new type of testing method. The mechanical detecting device is fixed on the outside of the pressure vessel, and the ultrasonic probe is used for scanning by the detecting rod to realize full-volume ultrasonic testing of the pressure vessel. After the control rod is parallel to the axis of the pressure vessel, when the detection rod is driven by the detecting rod lifting motor to complete a rising scan, the platform circumferential motor is started, and the platform is rotated $5^{\circ}$ around the axis of the pressure vessel on the rail. At this time, ensure that the ultrasonic probe is perpendicular to the outer wall of the pressure vessel, the detection rod rotating motor needs to rotate the same angle. Start the lifting motor of the detection rod, drive the detection rod to complete a descending sweep, when it reaches the bottom of the pressure vessel, start the circumferential motor of the detection platform again, drive the platform to rotate 5 degrees around the axis of the pressure vessel, then complete a sweep cycle. Repeat several times until the entire pressure vessel is finished.

\section{Conclusions}

After testing and testing, the pressure vessel fatigue damage ultrasonic testing device can complete the automatic detection stably and reliably under the specified requirements. The development of pressure vessel ultrasonic testing device and technology has solved the shortcomings of pre-service and in-service automatic inspection of pressure vessels, solved the shortcomings of manual detection, such as low precision of detection data, easy leak detection, etc., and promoted the automation process of ultrasonic testing. In line with the response of the current era of automation. The development of this technology can be applied not only to pressure vessels, but also to wall inspection in other industries.

\section{References}

1. L. Shen, Q. Shen, T.C. Hao. T.T. 12, 87 (2017)

2. Pantelakis S, Papanikos, et al. P.S.N. 569 (2003)

3. L. Zhu, et al. P.V. 29(2), 42 (2012)

4. C. G. Lin, et al. Beijing, Atomic Energy Press. (2008)

5. S. Ma, Y. Luo, Q. Yin, et al. Energy Materials. John Wiley \& Sons, Inc. 493 (2015)

6. R.K. Jing, J.Z. Li, H.L. Zhou. F.E.M.T. 31(7), 28 (2012)

7. J. Wang, J.Z. Qian, T.Z. Che. N.T. 35(5) , 68 )2013

8. M.R. Sun, C.Z. Liu. E.D.E. (12), 89 (2014) 